\title{
BENTOS LITORÂNEOS DO NORDESTE ORIENTAL DO BRASIL. II. POVOAMENTOS DOS SUBTRATOS DUROS
}

\author{
PETRONIO ALVES COELHO \\ Departamento de Oceanografia, Universidade Federal de Pernambuco, Recife, PE, Brasil
}

e

MARILENA RAMOS-PORTO

Departamento de Pesca, Universidade Federal Rural de Pernambuco, Recife, PE, Brasil

\section{SYNOPSIS}

In the rocky and gravely bottoms there are endolithic and epilithic species, and some soft bottom species. It was possible to distinguish in these bottoms the following communities: 1) supralittoral rock; 2) upper mediolittoral rock; 3) lower mediolittoral rock; 4) infralittoral rock; 5) infralittoral gravel; 6) circalittoral rock; and 7) semi-obscure caves.

\section{Introdução}

Este trabalho é o segundo de uma série sobre as características gerais dos povoamentos bênticos do litoral oriental do Nordeste do Brasil, baseada nos trabalhos realizados na área, pelo Departamento de Oceanografia da Universidade Federal de Pernambuco, em 20 anos de atividade. Para este estudo foram utilizados dados publicados anteriormente por vários pesquisadores (Van Andel \& Laborel, 1964; Labanca, 1967-69; Kempf, 1970; Coelho, 1970 e Coelho et al. , 1973) e informações inéditas. O trabalho se restringe à área mais intensamente explorada pelo Departamento de Oceanografia, estando limitada ao litoral, desde a Coroa das Lavadeiras (Rio Grande do Norte) até a fóz do Rio São Francisco (fronteira Alagoas/Sergipe), onde foram realizadas cerca de 600 estaçóes oceanográficas e inúmeras coletas costeiras (com especial atenção aos arrecifes e aos estuários).

A área continental correspondente ao litoral estudado foi descrita recentemente pela Fundação Instituto Brasileiro de Geografia e Estatística (1977); informaçõ̃es sobre as condiçōes hidrológicas e sedimentológicas estão contidas em vários trabalhos (por exemplo: Cavalcanti et al., (1965-66); Brasil. D.H.N., 1968, 1969; Cavalcanti \& Kempf, 1967-69; Coelho, 1970; Coelho et al., 1973). Lira et al., 1978; Mabesoone \& Tinoco, 1965-66; Macêdo et al., 1973 e Neumann, 1969).

São considerados como duros os fundos rochosos de natureza orgánica (construídos por corais, briozoários, moluscos, algas calcárias, etc) ou mineral (rochas magmáticas, sedimentares, etc.), assim como substratos sólidos de qualquer outra natureza (troncos e raizes de árvores, madeiras, pilares de pontes, cais, etc.). Os fundos cascalhosos, constituídos na área principalmente por nódulos de algas calcárias (Rhodophyceae do grupo das Melobesiae) ou por fragmentos calcários de organismos animais ou vegetais, possuem povoamento semelhante ao dos fundos rochosos e, por este motivo, estão considerados como fundos duros. Assim considerados, os fundos duros se encontram em todas as profundidades, porém, predominam desde as proximidades da isóbata de 20 metros até as vizinhanças da borda externa da plataforma continental.

\section{Natureza dos Povoamentos}

Do ponto de vista das relações com o substrato, são reconhecidas duas categorias principais de espécies nos substratos duros: epilíticas e endolíticas. As espécies epilíticas são encontradas vivendo sobre o substrato; algumas vivem permanentemente fixas ao substrato, como as algas, os celenterados. as esponjas, os briozoários, as ascídias, etc., assim como alguns poliquetas, moluscos e crustáceos: são as espécies sésseis; outras se deslocam lentamente sobre o substrato, como a maioria dos gastrópodos, dos placóforos e dos equinodermas, assim como numerosos poliquetas e crustáceos: são as espécies sedentárias. As espécies endolíticas vivem no interior ou ao abrigo do substrato, tais como certas esponjas e moluscos perfuradores das rochas calcárias, ou certos moluscos e crustáceos perfuradores das madeiras. Além destas categorias, são encontradas espécies indiferentes quanto à natureza do fundo, quase sempre dotadas de grande vagilidade, e organismos epibiontes sobre as espécies sésseis. Nos fundos rochosos e cascalhosos sempre existem encraves de fundos arenosos ou lamosos permitindo a existencia de espécies endopsâmicas e epipsâmicas.

São reconhecidos sete povoamentos, descritos à seguir: 1 Rocha supralitoral; 2) Rocha mediolitoral superior; 3) Rocha mediolitoral inferior; 4) Rocha infralitoral; 5) Cascalho infralito- ral; 6) Rocha e cascalho infralitoral; 7) Grutas semi-obscuras. 1) Rocha supralitoral - São elementos básicos do povoamento: algas epilíticas e endolíticas microscópicas, gastrópodos (Prosobranchia da família Littorinidae), crustáceos (Isopoda do gệnero Ligia e Decapoda da familia Grapsidae) e são freqüentes os líquens, vários insetos (Thysanura e Diptera).

$\mathrm{Na}$ porção dos mangues constantemente emersa correspondente ao supralitoral é encontrado um povoamento de dupla origem: lado a lado se encontram representantes de uma fauna arborícola análoga à existente em outros tipos de florestas, e elementos típicos da fauna marinha da rocha supralitoral. Entre as espécies arborícolas são encontyados aracnídeos (Oribatei, Acarina, Pseudosescorpionida, Araneae, etc) e insetos (Thysanura, Orthoptera, Hemiptera, Lepidoptéra, Diptera, Coleoptera e Hymenoptera).

2) Rocha médiolitoral superior - $O$ povoamento se apresenta tanto mais exuberante quanto mais batida for a costa. A flora é constituída principalmente por microalgas e a fauna compreende gastrópodos (Prosobranchia dos gêneros Acmaea e Fissurella que podem ser predados pelo gastrópodo Thais que vive normalmente mais abaixo), insetos, crustáceos (Cirripedia, do gênero Chthamalus, e Decápoda da família Grapsidae) e outros. Freqüentemente são também encontradas algas multicelulares muito tolerantes à dessecação. A posição deste povoamento, em relacão ao nível do mar, é variável de acordo com o grau de exposiçāo da costa.

3) Rocha mediolitoral inferior - A flora é caracterizada pela presença de algas calcárias e de cinturas de algas multicelulares moles. Há dois tipos principais de algas calcárias, um formando camada vermelha delgada sobre o substrato e o outro construindo verdadeiras "cornijas" nos lugares mais batidos; entre as algas moles são comuns espécies dos gêneros Ulva, Enteromorpha, Valonia, etc. A fauna compreende poríferos, antozoários (vários Actiniaria), gastrópodos (Prosobranchia carnivoros como Thais), pelecípodos (das famílias Ostreidae e Mytilidae), poliquetas, insetos (Collembola), crustáceos (Cirripedia dos gêneros Tetraclita e Balanus, Isopoda principalmente nas cavidades das rochas, e Decapoda, entre os quais são mais freqüentes os, caranguejos da família Xantidae, principalmente dos gêneros Eriphia, Menippe, Pano. peus, e da família Grapsidae, como Pachygrapsus) e ascídias.

A porção dos mangues, dos pilares de ponte e as grutas, correspondente ao mediolitoral, posssui um povoamento análogo ao da rocha mediolitoral inferior. A abundância e a distribuição das espécies estão na dependência do regime de salinidade.

4) Rocha infralitoral - O povoamento possui flora e fauna muito ricos. A flora consiste num grande numero de gêneroś e de espécies de algas, seja Chlorophyta, Phaeophyta ou Rhodophyta, sendo mais freqüentes algumas espécies dos gêneros Cauleppa, $\mathrm{Ha}$. limeda, Dictyoptris, Dictyota, Sargassum, Galaxaura, Hypnea, etc.

A fauna engloba representantes da maioria das 'classes de animais marinhos.

As espécies endo e epilíticas constituem a parte mais característica da fauna. Existem sarcodinos (Foraminefera), poríferos (grande variedade de esponjas), hidrozoários (principalmente Hydroida e Hydrocorallina; entre estes últimos as espécies de Millepora têm grande destaque como construtoras), antozoários (Gorgonacea, Telestacea, Actiniaria, Madreporaria e Zoanthidea; os madreporários dos gêneros Mussismilia, Montastrea, Siderastrea, Agari. cia e Porites são corais construtores muito freqüentes), turbelários. briozoários, anfineuros (Polyplacophora), gastrópodos (Opisthobranchia e Prosobranchia; entre estes últimos, salientam-se os Vermetidae, construtores, encontrados principalmente na faixa de transição entre este povoamento e o da Rocha mediolitoral infe- 
nor), pelecípodos (raros, sendo a salientar certos Mytilidae (gênero Lithophaga), perfuradores do calcário), cefalópodos, poliquetas (especialmente Eunicidae e Amphinomidae), sipunculídeos, equiurídeos, picnogônilas, crustáceos (Isopoda, Amphipoda, Tanaidacea, Stomatopoda e Decapoda em grande variedade), crinóides, asteróides, equinoides (o ouriço Echinometra lucunter (L.) é uma das especies mais freqüentes), ofiuros, holotúrias, ascídias e peixes osseos. Entre estes últimos, salientam-se por sua abundância as familias Acanthuridae, Pomacentridae, Sparidae, Labridae, Apogonidae, Grammistida e, Grammidae, Holocentridae, Ephippidae, Murae nidae, Ophichthyidae, Serranidae, Carangidae, Clinidae, Gobiidae, Scorpaenidae, Pomadasýdae, Antennariidae, Chaetodontidae e várias outras.

Existe uma fauna e uma flora epifita comuns a este povoamento e ao da praia infralitoral.

Seria possivel distinguir numerosas fácies no povoamento, segundo a predominância desta ou daquela alga mole, da presença ou ausência de invertebrados ou algas construtores, etc. As especies construtoras podem recobrir a rocha subjacente ocultando-a totalmente.

5) Cascalho infralitoral. - Este povoamento é encontrado principalmente na porção inferior do infralitoral, entre 20 e $40 \mathrm{~m}$ de profundidade.

A flora está representada por algas Chlorophyta, Phaeophyta e Rhodophyta. Entre as rodofíceas predominam as algas calcárias do tipo Lithothamnium, as quais constituem a maior parte do cascalhos. Entre as algas moles são comuns as espécies dos gêneros Caulerpa, A vrainvillea e Bryotamnium, epífitas sobre as algas calcárias. ou enraizadas na porção mais fina do sedimento

A fauna compreende sarcodinos, poríferos, antozoários (Gorgonacea, Alcyonacea e Madreporia), escafópodos, gastrópodos los gêneros Turritella, Modulus, Alaba e Stylocheilus são frequentes), pelecípodos (os gêneros Anadara, Lyropecten, Laevicardium. Transenpitar, Gouldia, entre outros, ocorrem com freqüência), poliquetas, sipunculídeos, equiurídeos, picnogónidas, crustáceos (Isopoda, Amphipoda, Stomatopoda e Decapoda; os decápodos Micro phrys interruptus Rathbun e $M$, antillensis Rathbun estão entre as espécies mais comuns), asteróides, equinóides, ofiuros, ascídias, cefalocordados e peixes ósseos (principalmente das famílias Muraenidae, Scorpaenidae, Serranidae, Apogonidae, Chaetodontidae, Scaridae, Clinidae, Gobiidae, etc).

Este povoamento possui numerosas espécies comuns a outros povoamentos. Em primeiro lugar, há um contingente de espécies ciáfilas ou eurifóticas comuns aos povoamentos infralitorais e circalitorais de fundos duros. Além disto, várias espécies epífitas infralitorais são encontradas indiferentemente à natureza (dura ou móvel) dos fundos. Kempf (1970) exemplifica ambos os casos.

6) Rocha e cascalho circalitoral - A flora compreende Chlorophyta, Phaeophyta e Rhodophyta. As rodofíceas calcárias, em certos lugares, podem construir extensōes rochosas ou grandes blo$\cos$, enquanto em outros se reduz à nódulos, \&, até a lâminas delgadas recobrindo material de outra natureza. O cascalho é uma mistura, em proporções variáveis, de nódulos de algas calcárias e de restos otgânicos dẹ constituiçẫo calcária. As algas moles estão representadas por numerosas espécies, pertencentes a gêneros como Caulerpa, Halimeda, Udotea, Sargassum, Galaxaura, etc.

A fauna é menos rica que a do povoamento precedente. E possivel assinalar, no momento, a presença de sarcodinos, poríferos, hidrozoários (Hydrocorallina e Hydroida; entre os primeiros, Millepora braziliensis Verrill e $M$. alcicornia Linnaeus), antozoários (Gorgonacea, Alcyonacea e Madreporaria; os madreporários dos gêneros Madracis, Agaricia, Siderastraea, Porites, Montastrea, Scolymia, Mussismilia e Stephanocoenia, entre outros, parecem comuns), briozoários, gastrópodos (Opisthobranchia e Prosobranchia; entre estes últimos, certas espécies de Trivia e de Conus são típicas do povoamento), peleccípodos (como Glycimeris e Laevicardium), poliquetas, picnogốnidas, crustáceos (Amphipoda; Isopoda; Stomatopoda, entre os quáis são muitos comuns certas espécies dos gêneros Pseudosquilla, Meiosquilla e Gonodactylus; Decapoda, entre os quais predominam representantes dos gêneros Munida, Macrocoeloma, Stenorhynchus, Mithrax, Palicus, Melybia, Podochela, Lissa, etc.), equinóides, crinóides, ofiuros, holotúrias e peixes ńsseos (de familias como Muraenidae, Scorpaenidae, Serranidae, Chaetodontidae, Scaridae, Tetraodontidae, etc).
Não e bem conhecido o limite batimétrico intenor do povoamento. Ao largo de Tamandaré, Pernambuco, foi encontrado este povoamento até a profundidade de $100-110 \mathrm{~m}$, e povoamento batial a $150 \mathrm{~m}$. Foram realizadas coletas a profundidades comparáveis apenas defronte da fóz do $\mathrm{R}$ io São Francisco, as quais trouxeram amostras de povoamentos de fundos móveis.

7) Grutas semi-obscuras - Nas grutas submarinas dos arrecifes existe um povoamento de natureza circalitoral, caracterizado pela presença de organismos ciáfilos e eurifóticos. Devido à dificuldades na exploração do ambiente, o povoamento é mal conhecido. Estão assinalados certos sarcodinos, poriferos, hidrozoários ( $\mathrm{Hy}$ drodoida), antozoários (Telestacea e Madreporaria) e crustáceos (Decápoda, principalmente certos camarões de corpo avermelhado, ainda não coletados).

\section{Comentários}

A descrição dos povoamentos bênticos dos substratos duros, aqui apresentada, está baseada num estudo estático e não leva em consideração as possíveis variaçōes sazonais. Existem reunidos, dados demonstrando que os povoamentos situados mais superficialmente sofrem variações sazonais suficientemente grandes para mudar sua fisionomia.

\section{Bibliografia}

BRASIL. DIRETORIA DE HIDROGRAFIA E NAVEGAÇĀO 1968. XXXV Comissão oceanográfica. Operação Norte/Nordeste I. NOc. "Almirante Saldanha" - (14/9 a 16/12/1967). DG-26-XI

969. XXXVI Comissão oceanografica. Operação/Nordeste II. NOc. "Almirante Saldanha" - (2/4 a 1/6/1968), DG-26-XII.

CAVALCANTI, L.B. \& KEMPF, M. 1967-69. Estudo da plataforma continental na área do Recife (Brasil). II. Meteorologia e hidrologia. Trabhs oceanogr. Univ. fed. Pe., 9/11:149-158.

CAVALCANTI, L.B.; COELHO, P.A.; KEMPF, M.; MABESOONE, J.M. \& SILVA, O.C: da 1965-66. Shelf off Alagoas and Sergipe (Northeastern Brazil). I. Introduction. Trabhs Inst. Oceanogr. Univ, fed. Pe., 7/8:137-150.

COELHO, P.A. 1970. Estuários e lagunas do Nordeste. In : Vasconcelos Sobrinho, J. - As regiōes naturais do Nordeste, o meio e a civilização. Recife, Conselho do Desenvolvimento de Pernambuco, p. 49-60.

KOENING, M.L. \& RAMOS, M.A. 1973. A macrofauna bêntica dos estuários de Pernambuco e da Paraíba. Actas IV Congr. latinoam. Zool., 2 : 497-528.

FUNDAÇÃO INSTITUTO BRASILEIRO DE GEOGRAFIA E ESTATISTICA. DIRETORIA TÉCNICA. 1977. Geografia do Brasil: vol. 2, Região Nordeste. Rio de Janeiro, IBGE.

KEMPF, M. 1970. Notes on the benthic bionomy of the N-NE Brazilian shelf. Mar. biol., 5 (3): 213-224.

LABANCA. L. 1967-69. Contribuição ao conhecimento da flora algológica marinha do Nordeste brasileiro. Trabhs oceanogr. Univ. fed. Pe., 9/11:325-436.

LIRA, L.; ZAPATA, M.C.; FALCĀO, I.M. de M. \&OLIVEIRA Jr., A. V. de 1978. Material em suspensão, temperatura e salinidade no estuário do Rio Mamucaba-PE. Cad. Ômega. Univ. fed. rural Pe., 2 (1) : 97-116.

MABESOONE, J.M. \& TINOCO, I.M. 1965-66. Shelf off Alagoas and Sergipe (Northeastern Brazil). II. Geology. Trabhs Inst. oceanogr. Univ. fed. Pe., 7/8:151-186.

MACÊDO, S. J.; LIRA, M.E. F. \& SILVA, J.E. 1973. Condiçōes hidrológicas do Canal de Santa Cruz, Itamaracá, PE. I. Parte sul. Bolm Recursos nat., SUDENE, 11 (1/2) : 55-92.

NEUMANN, G, 1969. Seasonal salinity variations in the upper strata of the western tropical Atlantic Ocean. I. Sea surface salinities. Deep sea Res., 16 (suppl.) : 165-177.

Van ANDEL, T.H. \& LABOREL, J. 1964. Recent high relative sea level stand near Recife, Brazil. Science, N.Y., 145 (3632) : 580-581. 